\title{
Article \\ Thiol-Functionalization Carbonaceous Adsorbents for the Removal of Methyl-Mercury from Water in the ppb Levels
}

\author{
Evgenios Kokkinos ${ }^{1, *}$, Aggeliki Lampou ${ }^{1}$, Ioannis Kellartzis ${ }^{2}$, Dimitrios Karfaridis ${ }^{3}$ (D) \\ and Anastasios Zouboulis ${ }^{1}$ (D) \\ 1 Department of Chemistry, Aristotle University of Thessaloniki, 54124 Thessaloniki, Greece; \\ langeliki@chem.auth.gr (A.L.); zoubouli@chem.auth.gr (A.Z.) \\ 2 Department of Chemical Engineering, Aristotle University of Thessaloniki, 54124 Thessaloniki, Greece; \\ kellar.john@gmail.com \\ 3 Department of Physics, Aristotle University of Thessaloniki, 54124 Thessaloniki, Greece; \\ dkarfari@physics.auth.gr \\ * Correspondence: evgenios@chem.auth.gr
}

Citation: Kokkinos, E.; Lampou, A. Kellartzis, I.; Karfaridis, D.;

Zouboulis, A. Thiol-Functionalization Carbonaceous Adsorbents for the Removal of Methyl-Mercury from Water in the ppb Levels. Water 2022, 14, 49. https://doi.org/10.3390/ w14010049

Academic Editor: Antonio Zuorro

Received: 29 November 2021

Accepted: 23 December 2021

Published: 27 December 2021

Publisher's Note: MDPI stays neutral with regard to jurisdictional claims in published maps and institutional affiliations.

Copyright: (C) 2021 by the authors. Licensee MDPI, Basel, Switzerland. This article is an open access article distributed under the terms and conditions of the Creative Commons Attribution (CC BY) license (https:// creativecommons.org/licenses/by/ $4.0 /)$.

\begin{abstract}
Mercury is a highly toxic pollutant of major public health concern, and human exposure is mainly related to the aqueous phase, where its dominant form is methyl-mercury (MeHg). In the current work, two carbon-based adsorbents, i.e., a commercial activated carbon and a sunflower seeds' biochar, were modified by the introduction of thiol-active groups onto their surfaces for the $\mathrm{MeHg}$ removal from natural-like water in ppb concentration levels. The examined thiol-functionalization was a two-step process, since the raw materials were initially treated with nitric acid $(6 \mathrm{~N})$, which is a reagent that favors the formation of surface carboxyl groups, and subsequently by the thiol surface bonding groups through an esterification reaction in methanol matrix. The adsorbents' capacity was evaluated toward the $\mathrm{Hg}_{\text {total }}$ legislative regulation limit $(1 \mu \mathrm{g} / \mathrm{L})$ in drinking water (denoted as $Q_{1}$ ). The respective isothermal adsorption results revealed an increased affinity between $\mathrm{MeHg}$ and thiol-functionalized materials, where the commercial carbon showed slightly higher capacity $(0.116 \mu \mathrm{g} \mathrm{Hg} / \mathrm{mg})$ compared with the biochar $(0.108 \mu \mathrm{g} \mathrm{Hg} / \mathrm{mg})$. This variation can be attributed to the respective higher surface area, resulting, also, to higher thiol groups loading. Regarding the proposed mechanism, it was proved that the S-Hg bond was formed, based on the characterization of the best performed saturated adsorbent.
\end{abstract}

Keywords: thiol-functionalization; activated carbon; biochar; methyl-mercury; adsorption

\section{Introduction}

According to European Union policy, mercury is included in the list of priority pollutants for drinking water, as it presents high toxicity to living organisms. The effects on human health are associated with chronic poisoning, causing major neurological problems and vital organ dysfunction. Extensive studies have been conducted during the recent years, regarding the estimated safe for humans' annual dose of $\mathrm{Hg}$, with the corresponding concentration limit decreasing, as new data are continuously accumulated [1]. It is emphasized that the highly toxic methyl-mercury $(\mathrm{MeHg})$ is the main chemical specie, existing in the aqueous phase. When inorganic or elemental $\mathrm{Hg}$ enters water resources or seawater, the aforementioned $\mathrm{MeHg}$ can be formed through bacterial and/or phytoplankton actions [2].

The need to address the total concentration of mercury $\left(\mathrm{Hg}_{\text {total }}\right)$ is reflected in the extremely low Regulation Limit (RL) in drinking water, as clearly established by all international organizations. In particular, its concentration in water should not exceed $1 \mu \mathrm{g}$ $\mathrm{Hg}_{\text {total }} / \mathrm{L}(1 \mathrm{ppb})$ in order to be considered potable. This limit is the lowest among other toxic metals and, unlike other cases, it is accepted by both the European Union and the US Environmental Protection Agency (EPA). In addition, according to recent reports, the problem of MeHg environmental pollution is more intense in the Mediterranean region [3]. 
The relatively higher temperatures in combination with the volatility of this metal favor its mobility and, consequently, its appearance in water resources.

There are several known and, at least, laboratory-tested technologies for $\mathrm{Hg}$ or/and $\mathrm{MeHg}$ contaminated water treatment, such as adsorption, coagulation, filtration, and biological processes. However, up to now, only adsorption proved to be the better available technique for full-scale implementation, especially when the treated water is intended for drinking. Such distinction arises from the fact that the applied method should be capable of performing in low initial pollutant's concentration and, respectively, to present residual concentration of treated pollutants below the respective RL [4]. Moreover, adsorption may present high selectivity and minimum to no effects on water quality. In that framework, various materials have been tested as adsorbents for the $\mathrm{MeHg}$ removal from aquatic matrixes [5]. The most promising case proved to be the carbon-based materials, due to their potential, regarding the application of rather simple surface modification procedures [6], and also, due to composite formation of materials, i.e., forming binary materials with an inorganic phase [7].

Toward improved sustainability, several researchers have synthesized carbon-based materials, originating from agricultural wastes, such as biochar, in order to test them for the removal of toxic metals from contaminated waters [8]. Biochar may present high surface area values, similar to activated carbons, and as a result, can show high pollutant's adsorption capacities. On the other hand, the requirement of residual concentrations below the respective (mandatory) RL is generally hard to fulfill for the case of toxic metals without the proper surface modification. Especially for the case of $\mathrm{Hg}$, thiol active groups proved to be very efficient, increasing substantially the affinity between pollutant-adsorbent [9]. The removal mechanism follows the general HSAB theory (Hard and Soft Acids and Bases), where thiol as a soft alkali group prefers to bond with the soft acid mercury ions [10].

The above-mentioned mechanism was implemented in the literature mainly for the case of inorganic mercury $[9,10]$, but also for the removal of some other toxic metals from aquatic matrixes (water or/and waste streams) [11]. Moreover, when biochar was modified by thiol groups for improving the $\mathrm{MeHg}$ adsorption, the rather high initial concentrations of this pollutant was initially used in the literature studies [12]. However, in this work, lower initial $\mathrm{MeHg}$ concentrations were applied, i.e., closer to the real (environmental) ones, by using a typical commercial activated carbon, as well as a biochar produced by sunflower seeds, as adsorbents. These materials were selected in order to be proved that biochar may present competitive adsorption efficiency regarding the removal of $\mathrm{MeHg}$ from water, promoting also a sustainable way for the agricultural waste valorization. Initially, both were properly modified by introducing thiol groups on their surface, in order to present increased selectivity against the $\mathrm{MeHg}$ removal from natural-like water (simulated), aiming at the S-Hg bond formation. The two carbon-based adsorbents were thiol-functionalized by following a two-step process, applying aquatic and organic matrixes, and, as a result, $\mathrm{MeHg}$ residual concentration close to its RL were obtained. Their evaluation performed according to the corresponding capacity $Q_{R L}$, which is mentioned hereafter as $Q_{1}$.

\section{Materials and Methods}

\subsection{Adsorbents}

The commercial activated carbon CarboTech D45/2 supplied by DMT Modern Fuels Unit (Essen, Germany, material's reference in the text hereafter as D45). The biochar was prepared by pyrolyzing sunflower seeds for $0.5 \mathrm{~h}$ at $800^{\circ} \mathrm{C}$ and for $0.5 \mathrm{~h}$ at $900{ }^{\circ} \mathrm{C}$. Then, the biochar activated chemically by re-pyrolyzing it in the presence of potassium hydroxide, applying the ratio biochar/KOH equal to $1: 4$, for $1 \mathrm{~h}$ at $400{ }^{\circ} \mathrm{C}$ and for $1 \mathrm{~h}$ at $800{ }^{\circ} \mathrm{C}$ (material's reference in the text hereafter as $\mathrm{SF} / \mathrm{KOH}$ ). Both materials were grounded and sieved to obtain granules in the size range $63-125 \mu \mathrm{m}$. 


\subsection{Thiol-Functionalization}

The surface modification of examined adsorbent materials was conducted in two steps. Initially, $1 \mathrm{~g}$ of them was placed in a beaker, and $10 \mathrm{~mL}$ of $6 \mathrm{~N} \mathrm{HNO}_{3}$ were added. The mixture was stirred for $4 \mathrm{~h}$ at $90^{\circ} \mathrm{C}$, and then, it was separated by filtration. The solid phase was washed out with distilled water until a neutral $\mathrm{pH}$ was obtained for the filtrate, and it was dried at $50{ }^{\circ} \mathrm{C}$ for $1 \mathrm{~h}$ (materials' reference in the text hereafter as $\mathrm{D}_{4}{ }_{-} \mathrm{HNO}_{3}$ and $\mathrm{SF} / \mathrm{KOH} \mathrm{HNO}_{3}$, respectively. During the second activation step, $1 \mathrm{~g}$ of the acid-treated material was placed in a sealed beaker, and $2.5 \mathrm{~mL}$ of 2-mercaptoethanol (purchased by J.T. Baker) $/ 10 \mathrm{~mL}$ of distilled water or methanol solution was added. The mixture was stirred for $4 \mathrm{~h}$ at $50{ }^{\circ} \mathrm{C}$ and then filtered. The thio-functionalized material was washed out with distilled water several times in order to remove the reagent's excess and was dried at $50{ }^{\circ} \mathrm{C}$ for $1 \mathrm{~h}$ (materials' reference in the text hereafter as D45-SH_ $\mathrm{H}_{2} \mathrm{O}$ and SF/KOH-SH_H $\mathrm{H}_{2} \mathrm{O}$ for water matrix and D45-SH_MeOH and SF/KOH-SH_MeOH for methanol matrix).

\subsection{Adsorbents Characterization}

The method ASTMD 5373-93 [13] was used for the elementary analysis of the examined carbonaceous adsorbents, during which the carbon, hydrogen, nitrogen, sulfur and oxygen content was determined. The elemental analysis experiments were performed by using a Thermo Finnigan Flash EA 1112 CHNS analyzer. The specific surface area was estimated by the isotherms of adsorption and desorption of liquid nitrogen at $-196^{\circ} \mathrm{C}$, according to the BET (Brunauer-Emmett-Teller) model. The FT-IR (Fourier-Transformed Infra-Red) spectra of the samples were recorded in KBr media, using a Perkin-Elmer Spectrum 100 spectrophotometer. The fine sample powder was pelletized with $\mathrm{KBr}$ powder for the FT-IR study, aiming to reveal the major (surface) bond vibrations.

X-ray Photoelectron Spectroscopy (XPS) was applied to identify the sulfur and $\mathrm{MeHg}$ speciation after its uptake by the adsorbents. The spectrum was acquired in an Axis Ultra DLD system by KRATOS, where a mono-chromator Al-Ka1 X-ray beam was used as the excitation source. The pass energy was $160 \mathrm{eV}$ for the survey scans and $40 \mathrm{eV}$ for the high-resolution spectra. The spectra were calibrated in terms of charging-induced shifts by considering the $C 1$ s peak originating from the carbon surface contamination, and located at $284.6 \mathrm{eV}$.

\subsection{Adsortpion Evaluation}

A $50 \mathrm{mg} / \mathrm{L} \mathrm{Hg}$ (II) stock solution was prepared by dissolving $62.58 \mathrm{mg}$ of reagent grade $\mathrm{CH}_{3} \mathrm{HgCl}$ in a small volume of $\mathrm{HCl}$ (1:1) and diluting it to $1 \mathrm{~L}$ with distilled water. The working standard solutions were prepared by the proper dilution of stock solution in natural-like water, according to the National Sanitation Foundation (NSF, Ann Arbor, MI, USA) protocols. The NSF water was prepared by the dilution of $252 \mathrm{mg} \mathrm{NaHCO}_{3}$, $12.14 \mathrm{mg} \mathrm{NaNO}, 0.178 \mathrm{mg} \mathrm{NaH} \mathrm{PO}_{4} \cdot \mathrm{H}_{2} \mathrm{O}, 2.21 \mathrm{mg} \mathrm{NaF}, 70.6 \mathrm{mg} \mathrm{NaSiO} \cdot 5 \mathrm{H}_{2} \mathrm{O}, 147 \mathrm{mg}$ $\mathrm{CaCl}_{2} \cdot 2 \mathrm{H}_{2} \mathrm{O}$, and $128.3 \mathrm{mg} \mathrm{MgSO} \cdot 7 \mathrm{H}_{2} \mathrm{O}$ in $1 \mathrm{~L}$ of distilled water. Prior to adsorption experiments, the $\mathrm{pH}$ adjusted to the target value by adding drops of either $\mathrm{NaOH}$ or $\mathrm{HNO}_{3}$ $(0.1 \mathrm{~N})$.

The adsorption isotherms were recorded according to batch experiments in order to evaluate the $\mathrm{MeHg}$ uptake and estimate the corresponding capacity, aiming to achieve residual concentration of $\mathrm{Hg}$ equal to the regulation limit of $1 \mu \mathrm{g} / \mathrm{L}\left(\mathrm{Q}_{1}\right)$. In a conical flask, $20-150 \mathrm{mg}$ of the adsorbent material was placed and equilibrated with $200 \mathrm{~mL}$ of the $\mathrm{MeHg}$ solutions (in NSF matrix) with the initial concentration of $500 \mu \mathrm{g} \mathrm{Hg} / \mathrm{L}$. The $\mathrm{pH}$ value was adjusted to 7 , the flask was shaken for $24 \mathrm{~h}$, and afterwards, the suspension was filtered.

The residual $\mathrm{MeHg}$ concentrations in the filtrate were determined by a Bacharach Coleman-Model 50B cold vapor mercury analyzer system (Figure S1), following a method that was optimized in previously published research [14]. In brief, the aquatic samples were pre-treated by adding $0.005 \% w / v \mathrm{KMnO}_{4}$ and $0.05 \% w / v \mathrm{NaBH}_{4}$; the latter was needed for the reliable $\mathrm{MeHg}$ measurement as a reducing agent for the atomization of mercury. 


\section{Results}

\subsection{Characterization of Examined Adsorbents}

The elemental analysis of carbonaceous materials, in which the thiol-functionalization process was applied, is presented in Table 1. As expected, they consisted mainly of carbon and oxygen, while nitrogen and sulfur were under the detection limit concentration for the case of SF/KOH. In Figure 1, the IR spectra of D45 and SF/KOH materials showed similar main vibration stretching bonds. The wide peaks at $1632 \mathrm{~cm}^{-1}$ for the D45 and at $1620 \mathrm{~cm}^{-1}$ for the $\mathrm{SF} / \mathrm{KOH}$ adsorbents were attributed to $\mathrm{C}=\mathrm{O}, \mathrm{C}-\mathrm{O}$, and $\mathrm{C}=\mathrm{C}$ bonds [9]. The sharp peaks at $1387 \mathrm{~cm}^{-1}$ and $1123 \mathrm{~cm}^{-1}$ for the D45 and at $1382 \mathrm{~cm}^{-1}$ and $1124 \mathrm{~cm}^{-1}$ for the $\mathrm{SF} / \mathrm{KOH}$ samples were related to $\mathrm{C}-\mathrm{H}$ and C-O (alkoxyl) bonds vibration, respectively [15]. Regarding the surface area, the produced biochar presented competitive value when compared to the commercial activated carbon.

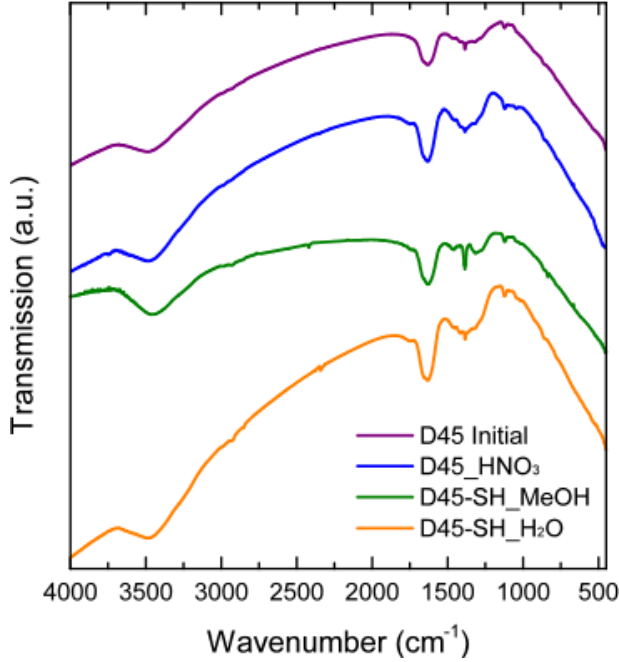

(a)

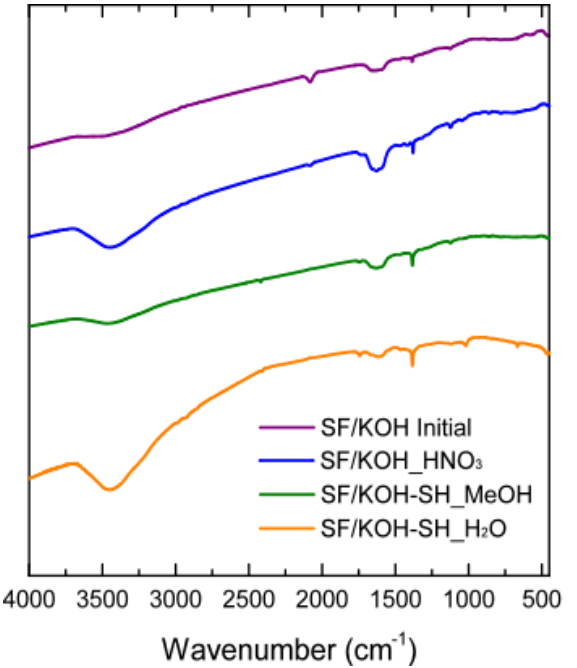

(b)

Figure 1. IR spectra of initial materials, as well as after every corresponding treatment stage, i.e., by $\mathrm{HNO}_{3}$, by thiol-functionalization with $\mathrm{MeOH}$, or by water matrix: (a) D45; (b) SF/KOH.

Table 1. Elemental analysis and surface area of the carbonaceous materials.

\begin{tabular}{ccccccc}
\hline Sample & $\mathbf{C}$ & $\mathbf{H}$ & $\mathbf{N}$ & $\mathbf{S}$ & $\mathbf{O}$ & $\mathbf{B E T}$ \\
\hline & & & $\boldsymbol{\%} \boldsymbol{w} / \boldsymbol{w}$ & & & $\mathbf{m}^{2} / \mathbf{g}$ \\
\hline $\mathrm{D} 45$ & 87.6 & 0.53 & 0.37 & 0.68 & 10.8 & 1230 \\
\hline $\mathrm{SF} / \mathrm{KOH}$ & 71.7 & 0.20 & $\mathrm{ND}$ & $\mathrm{ND}$ & 28.1 & 928 \\
\hline
\end{tabular}

\subsection{Thiol-Functionalization Mechanism}

The thiol-functionalization of the activated carbons' surface was considered to be a two-step process in order to be optimized under the applied conditions. Initially, the sorbent was treated by nitric acid, which favors the formation of surface carboxyl groups. Nitric acid is the most widespread relevant reagent, since it reaches the highest carboxyl distribution among the use of other oxidants (i.e., hydrochloric acid, sulfuric acid, etc.) [16]. According to the IR spectra of $\mathrm{HNO}_{3}$-treated materials (Figure 1), the peaks at $1755 \mathrm{~cm}^{-1}$ for the case of $\mathrm{D} 45 \mathrm{HNO}_{3}$ and at $1743 \mathrm{~cm}^{-1}$ for the $\mathrm{SF} / \mathrm{KOH} \mathrm{HNO}_{3}$ were attributed to vibration stretching of the bond $\mathrm{C}=\mathrm{O}$ relevant to carboxyl groups [17]. The aforementioned peaks were absent from the corresponding diagrams of the initial materials, indicating that carboxyl groups introduced onto D45 and SF/ KOH surfaces by the $\mathrm{HNO}_{3}$ treatment.

The process of introducing thiol groups onto the carbon surface is mainly based on the application of appropriate reagent. In this study, 2-mercaptoethanol was used, which has a thiol group at one end of the molecule and a hydroxyl group at the other 
end. The purpose of the carboxyl groups' formation was fulfilled during the second step, where an esterification reaction between them and the hydroxyl end took place [9]. As supported by IR spectra of thiol-modified materials in both aquatic or organic matrixes, the weak peaks at $2429 \mathrm{~cm}^{-1}$ for the case of D45-SH_MeOH $3,2351 \mathrm{~cm}^{-1}$ for D45-SH_H $\mathrm{H}_{2} \mathrm{O}$, $2422 \mathrm{~cm}^{-1}$ for SF/KOH-SH_MeOH, and $2430 \mathrm{~cm}^{-1}$ for SF $/ \mathrm{KOH}-\mathrm{SH} \mathrm{H}_{2} \mathrm{O}$ were attributed to the vibration stretching of the S-H bond [10]. Moreover, the sulfur content increased in thiol-functionalized materials, according to the elemental analysis data (Table 2). Due to the surface modification, the percentage distribution of all elements changed as well as the specific surface area, which showed a decrease of $33 \%$ or $36 \%$ for the cases of D45SH_MeOH or SF/KOH-SH_MeOH, respectively. When the water matrix was used, the surface area showed reduction equal to $29 \%$ for the case of D45-SH_ $\mathrm{H}_{2} \mathrm{O}$ and $31 \%$ for $\mathrm{SF} / \mathrm{KOH}-\mathrm{SH}_{-} \mathrm{H}_{2} \mathrm{O}$, since the 2-mercaptoethanol load was lower, limiting the respective pores' blockages [18].

Table 2. Elemental analysis and surface area of the thiol-functionalized carbonaceous materials.

\begin{tabular}{|c|c|c|c|c|c|c|}
\hline Sample & $\mathrm{C}$ & $\mathbf{H}$ & $\mathbf{N}$ & $S$ & $\mathrm{O}$ & BET \\
\hline & & & $(\% w / w$ & & & $\left(\mathrm{m}^{2} / \mathrm{g}\right)$ \\
\hline D45-SH_MeOH & 78.4 & 3.45 & 2.83 & 3.21 & 12.1 & 826 \\
\hline $\mathrm{D} 45-\mathrm{SH}_{-} \mathrm{H}_{2} \mathrm{O}$ & 79.1 & 2.93 & 2.64 & 2.97 & 12.4 & 872 \\
\hline SF/KOH-SH_MeOH & 68.9 & 1.94 & 1.92 & 2.08 & 25.2 & 594 \\
\hline $\mathrm{SF} / \mathrm{KOH}-\mathrm{SH} \mathrm{H}_{2} \mathrm{O}$ & 69.5 & 2.25 & 2.14 & 1.82 & 24.3 & 637 \\
\hline
\end{tabular}

\subsection{Methylmercury Adsorption}

Aiming to apply quite realistic conditions during the evaluation of D45-SH and $\mathrm{SF} / \mathrm{KOH}-\mathrm{SH}$ materials, regarding $\mathrm{MeHg}$ removal, the natural-like water (according to NSF) was applied at $\mathrm{pH} 7$ in order to obtain the adsorption isotherms. Moreover, the initial $\mathrm{MeHg}$ concentration was $500 \mu \mathrm{g} \mathrm{Hg} / \mathrm{L}$, attempting to fulfill two aspects, i.e., residual concentrations close to RL and valid fitting by the applied isothermal models.

Regarding the isothermal models, those of Freundlich $\left[\mathrm{Q}_{\mathrm{e}}=\mathrm{K}_{\mathrm{F}} \cdot \mathrm{C}_{\mathrm{e}}{ }^{1 / \mathrm{n}}\right]$ and of Langmuir $\left[\mathrm{Q}_{\mathrm{e}}=\mathrm{Q}_{\max } \cdot \mathrm{K}_{\mathrm{L}} \cdot \mathrm{Ce} /\left(1+\mathrm{K}_{\mathrm{L}} \cdot \mathrm{C}_{\mathrm{e}}\right)\right]$ are the most widespread adsorption equations, considering liquid phase adsorption. $\mathrm{Q}_{\mathrm{e}}$ represents the amount of adsorbed metals per mass of adsorbent at the equilibrium concentration $\mathrm{C}_{\mathrm{e}}, \mathrm{Q}_{\max }$ is the maximum adsorption capacity, $\mathrm{K}_{\mathrm{F}}$ and $\mathrm{n}$ are the Freundlich constants related to adsorption capacity and intensity, and $\mathrm{K}_{\mathrm{L}}$ is the Langmuir constant [19-21].

The isothermal data and the corresponding equations' fitting are presented in Figure 2. All modified materials showed high correlation for both models, which is attributed to the rather low adsorption load and consequently, they represent monolayer coverage. On the other hand, when the initial non-modified materials were applied, at the same experimental conditions, zero correlation was presented for both isothermal models and high residual MeHg concentration. 


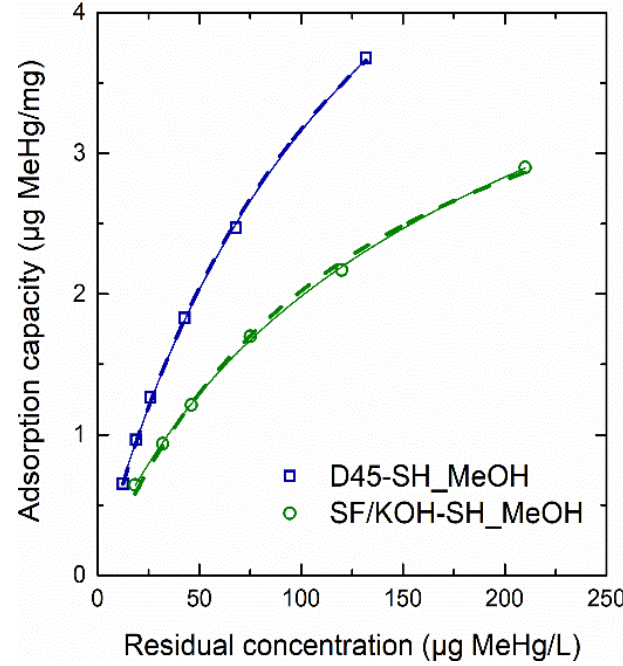

(a)

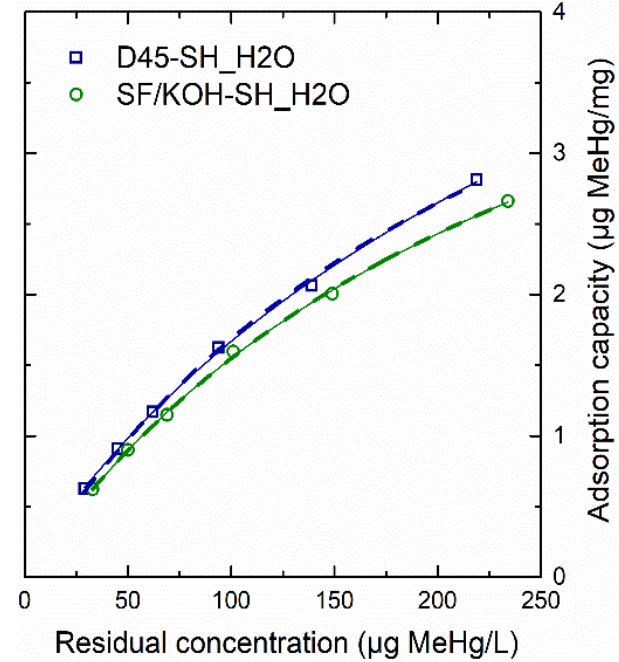

(b)

Figure 2. Adsorption isotherms of thio-functionalized materials in NSF water at $\mathrm{pH} 7$. Solid lines represent the Freundlich model and dashed lines represent the Langmuir model: (a) MeOH matrix; (b) $\mathrm{H}_{2} \mathrm{O}$ matrix.

As a result, the evaluation of adsorption capacity of the resulting materials in every modification step conducted through the $\mathrm{MeHg}$ residual concentration by applying the same experimental conditions (i.e., $500 \mu \mathrm{g} \mathrm{Hg} / \mathrm{L}, 750 \mathrm{mg}$ adsorbent/L, use of NSF water, $\mathrm{pH} 7$ ). According to Figure 3, the treatment of raw carbonaceous materials with nitric acid (i.e., the samples $\mathrm{D} 45 \mathrm{HNO}_{3}$ and $\mathrm{SF} / \mathrm{KOH} \mathrm{HNO}_{3}$ ) caused a significant reduction of sorbent's efficiency, so higher MeHg residual concentrations were observed. This can be attributed to the formation of surface carboxyl groups, which are considered as acidic sites [16] and therefore, the HSAB mechanism with the (similarly) acidic MeHg is not favored. The substantial reduction of residual $\mathrm{MeHg}$ concentration observed with the use of thiol-functionalized materials (i.e., with the samples D45-SH_MeOH and SF/KOH$\mathrm{SH}$ _MeOH) as the acidic carboxyl groups participated in the esterification reaction and new basic active thiol groups were introduced [10].

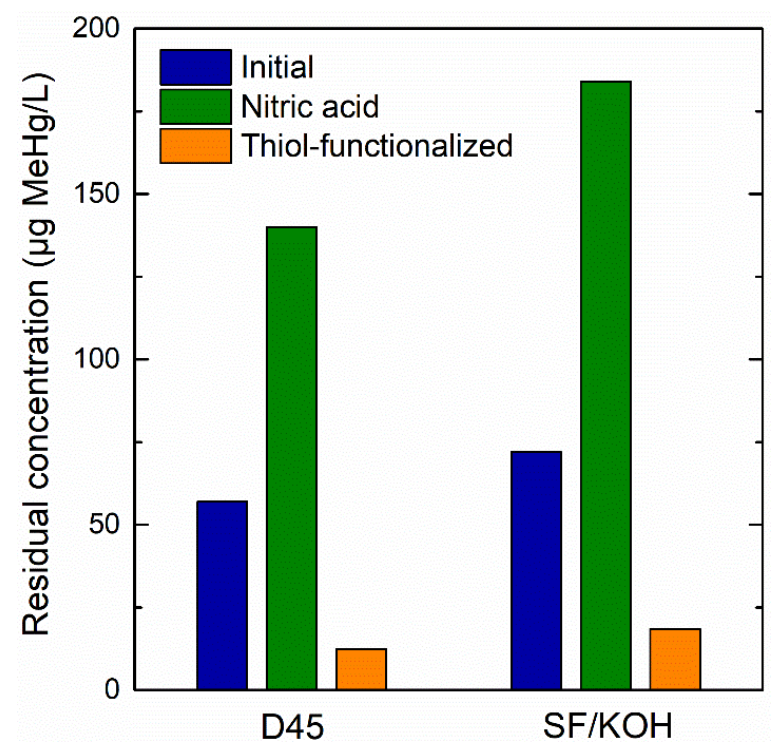

Figure 3. Residual concentration of MeHg in every step of $\mathrm{D} 45$ and SF/ $\mathrm{KOH}$ modification process under the same experimental conditions, i.e., $500 \mu \mathrm{g} \mathrm{Hg} / \mathrm{L}, 750 \mathrm{mg}$ adsorbent/L, NSF water, pH 7. 
According to Table 3, where the estimated fitting parameters of the applied models are presented, the D45-SH_MeOH material showed the highest MeHg capacity at RL $\left(\mathrm{Q}_{1}=0.116 \mu \mathrm{g} / \mathrm{mg}\right)$. The respective capacity of SF/KOH-SH_MeOH was found to present a slightly lower $Q_{1}$ value $(0.108 \mu \mathrm{g} / \mathrm{mg})$, which is related to the relevant smaller surface area and lower sulfur content (Table 1). For the same reasons, D45-SH_H ${ }_{2} \mathrm{O}$ and SF/KOHSH_H ${ }_{2} \mathrm{O}$-modified adsorbents showed reduced capacities (approximately by half) when compared with the aforementioned values, i.e., $0.054 \mu \mathrm{g} / \mathrm{mg}$ and $0.048 \mu \mathrm{g} / \mathrm{mg}$, respectively. When aqueous matrix was used in the thiol-factualization step, then the dispersion of adsorbent was decreased in comparison with the use of methanol as solvent, and lower rates of thiol group formation on the same surface and for the same time can be expected [22].

Table 3. Estimated fitting parameters of Freundlich and Langmuir main adsorption models.

\begin{tabular}{|c|c|c|c|c|c|c|c|}
\hline \multirow[b]{2}{*}{ Adsorbent } & \multirow{2}{*}{$\begin{array}{c}Q_{1} \\
\mu \mathrm{g} / \mathrm{mg}\end{array}$} & \multicolumn{3}{|c|}{ Freundlich Parameters } & \multicolumn{3}{|c|}{ Langmuir Parameters } \\
\hline & & $\begin{array}{c}\mathrm{K}_{\mathrm{F}} \\
\mu \mathrm{g} / \mathrm{mg}(\mu \mathrm{g} / \mathrm{L})^{-1 / n}\end{array}$ & $1 / \mathbf{n}$ & $\mathbf{R}^{2}$ & $\begin{array}{c}\mathrm{K}_{\mathrm{L}} \\
\mathrm{L} / \mu \mathrm{g}\end{array}$ & $\underset{\mu \mathrm{gax} / \mathrm{mg}}{\mathrm{Q}_{\max }}$ & $\mathbf{R}^{2}$ \\
\hline D45-SH_MeOH & 0.116 & 0.116 & 0.72 & 0.993 & 0.009 & 6.8 & 0.997 \\
\hline D45-SH_H ${ }_{2} \mathrm{O}$ & 0.054 & 0.054 & 0.74 & 0.997 & 0.004 & 5.7 & 0.993 \\
\hline SF/KOH-SH_MeOH & 0.108 & 0.108 & 0.63 & 0.993 & 0.008 & 4.5 & 0.992 \\
\hline $\mathrm{SF} / \mathrm{KOH}-\mathrm{SH} \mathrm{H}_{-} \mathrm{H}_{2} \mathrm{O}$ & 0.048 & 0.048 & 0.74 & 0.993 & 0.004 & 5.7 & 0.995 \\
\hline
\end{tabular}

In addition, the $\mathrm{Q}_{1}$ values of the thiol-functionalized biochar were revealed, as well as the crucial role of sulfur content in the $\mathrm{MeHg}$ removal, since the sample SF/KOH-SH_H ${ }_{2} \mathrm{O}$ presented higher surface area but lower capacity when compared with the sample $\mathrm{SF} / \mathrm{KOH}$ SH_MeOH. Therefore, it was concluded that the adsorption efficiency mainly depends on the -SH load and partially the surface area during adsorption, since the BET values were slightly different between these samples (Table 2) [18]. However, an attempt to correlate the sulfur content of all materials with the respective performance is not possible, since the D45$\mathrm{SH}_{-} \mathrm{H}_{2} \mathrm{O}$ showed a higher sulfur percentage and surface area, but lower MeHg capacity, in comparison with the SF/KOH-SH_MeOH. In fact, the oxidation of thiols is extremely likely to take place [23], mainly to disulfides (-S-S-) [24]; hence, the use of an organic solvent (as is the methanol in the present study) is preferred during the thiol-functionalization, instead of the use of an aquatic solvent in order to keep the -SH groups stable [11].

Furthermore, the main Langmuir parameter $\mathrm{Q}_{\max }$ should be considered as invalid, since a relatively low $\mathrm{MeHg}$ initial concentration was used and correspondingly, lower $\mathrm{MeHg}$ loading onto the adsorbent surface was achieved. As a result, the limited accuracy of isotherm's extrapolation indicates that the SF/KOH-SH_ $\mathrm{H}_{2} \mathrm{O}$ material showed higher maximum capacity, even if the models' affinity relevant constants $\left(\mathrm{K}_{\mathrm{F}}, \mathrm{n}\right.$ and $\left.\mathrm{K}_{\mathrm{L}}\right)$ may support the opposite [25].

\subsection{Adsorption Mechanism}

The modified D45-SH_MeOH material was found to be the best among the examined, according to the isothermal data, regarding the removal of $\mathrm{MeHg}$, and it was used to further investigate the adsorption mechanism. The XPS spectra of the D45-SH_MeOH adsorbent before and after the $\mathrm{MeHg}$ adsorption (Figure 4a) came in agreement with the respective chemical/elemental analysis, showing that the main elements of its composition were carbon, oxygen, and sulfur. Moreover, the presence of the $\mathrm{Hg} 4 \mathrm{f}$ peak in the saturated sample (after use) indicated the MeHg adsorption. 


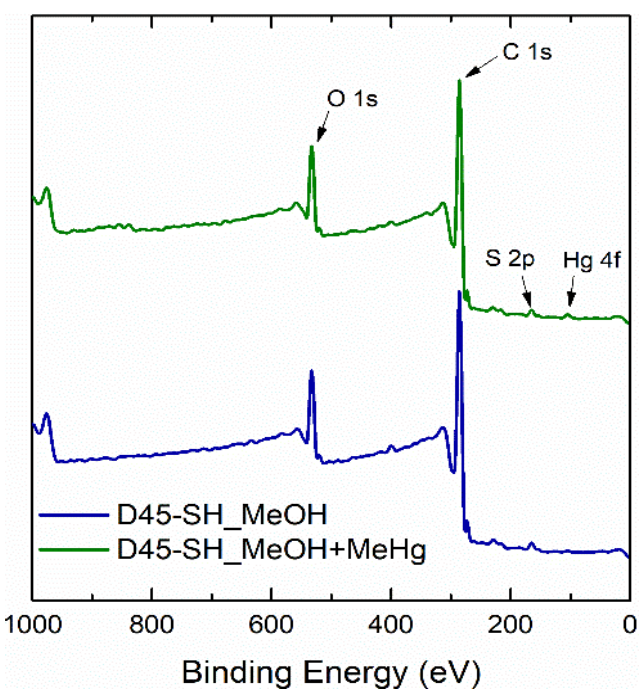

(a)

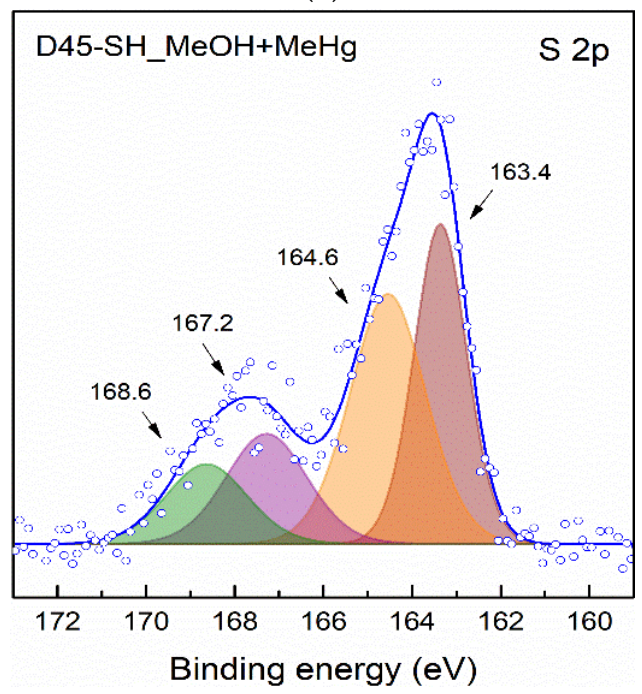

(c)

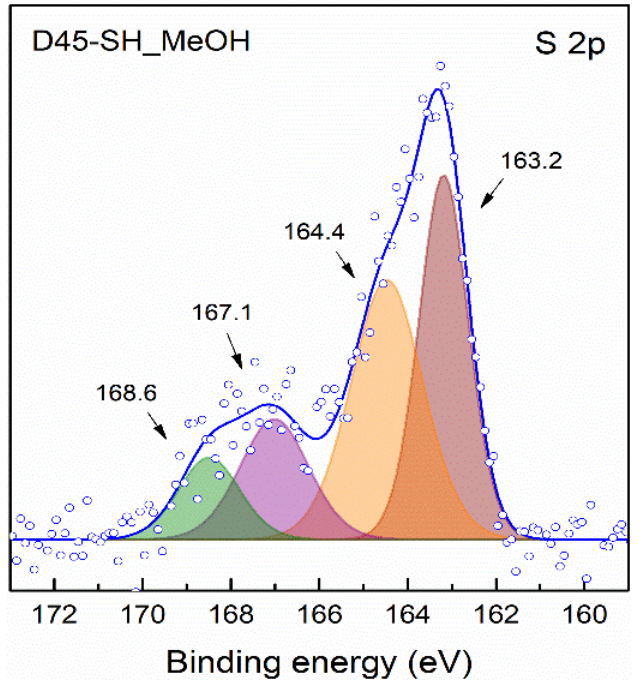

(b)

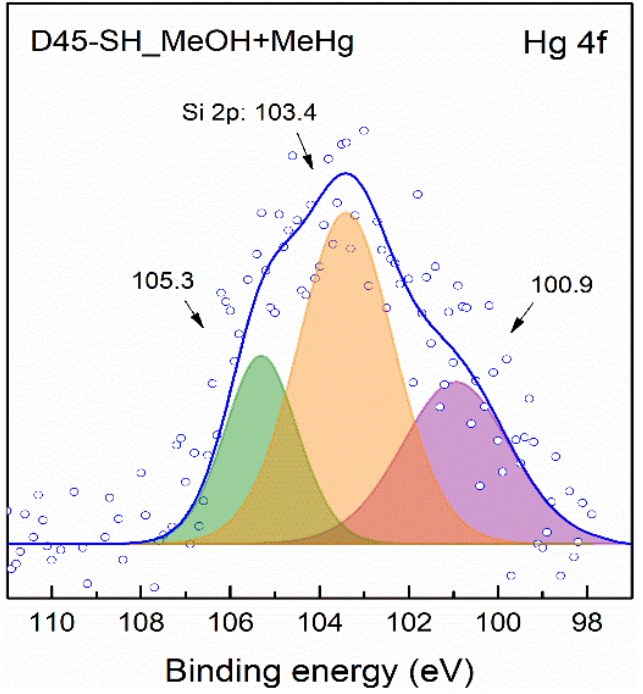

(d)

Figure 4. XPS spectra of D45-SH_MeOH material before and after the MeHg adsorption; (a) highresolution S 2p core-level spectra of this material (b) before and (c) after the $\mathrm{MeHg}$ adsorption, and the $\mathrm{Hg} 4 \mathrm{f}$ core-level spectra of D45-SH_MeOH material after the MeHg adsorption (d).

The high resolution of S 2p core-level spectra for the D45-SH_MeOH material before and after the $\mathrm{MeHg}$ adsorption are presented in Figure $4 b, c$, respectively. In both cases, the S 2p spectra showed two pair of peaks, which correspond to different sulfur bonds/modes. The pair of peaks in the range $163-165 \mathrm{eV}$ was attributed to $S 2 \mathrm{p}_{1 / 2}$ and $2 \mathrm{p}_{3 / 2}$ of the C-S bond, due to the $-\mathrm{SH}$ groups, [26], whereas the pair in the range 167-169 eV was attributed to $2 \mathrm{p}_{1 / 2}$ and $2 \mathrm{p}_{3 / 2}$ of oxidized sulfur or/and sulfur oxides [12,18]. Moreover, the second $\mathrm{S}$ $2 p$ double peak confirmed the previous hypothesis of the partial oxidation of the introduced thiols. A slight increase in $S 2 p_{1 / 2}$ and $2 p_{3 / 2}$ peaks, related with the $-S H$ groups, were observed after $\mathrm{MeHg}$ adsorption, i.e., from $163.2 \mathrm{eV}$ and $164.4 \mathrm{eV}$ to $163.4 \mathrm{eV}$ and $164.6 \mathrm{eV}$ (splitting factor equal to $1.2 \mathrm{eV}$ ), respectively. This indicated that the thiols involved in the $\mathrm{HSAB}$ reaction with $\mathrm{MeHg}$ and, also, the sulfur atoms donated electrons in order to form the $\mathrm{S}-\mathrm{Hg}$ bond $[27,28]$. On the other hand, the $\mathrm{S} 2 \mathrm{p}_{1 / 2}$ and $2 \mathrm{p}_{3 / 2}$ peaks correlated well with the structured sulfur oxides (Table 1 ) and oxidized thiols, showing negligible to no bond energy changes, and confirming their zero participation in the removal mechanism (i.e., from $167.1 \mathrm{eV}$ and $168.6 \mathrm{eV}$ to $167.2 \mathrm{eV}$ and $168.6 \mathrm{eV}$, respectively). The same conclusion resulted also by the high resolution of $\mathrm{O} 1 \mathrm{~s}$ and $\mathrm{C}$ 1s core-level spectra (Figure S2). 
In Figure 4d, the high resolution of $\mathrm{Hg} 4 \mathrm{f}$ core-level spectra is presented, regarding the saturated D45-SH_MeOH material. The binding energies $105.3 \mathrm{eV}$ and $100.9 \mathrm{eV}$ were related with $\mathrm{Hg} 4 \mathrm{f}_{5 / 2}$ and $4 \mathrm{f}_{7 / 2}$, respectively, indicating the successful MeHg adsorption, while the peak at $103.4 \mathrm{eV}$ is attributed to the Si 2 p core level $[10,29]$.

\section{Discussion}

Carbonaceous materials, such as those examined in this study, namely the commercial activated carbon (D45) and the sunflower seeds biochar (SF/KOH), are low-cost adsorbents and, moreover, the second one promotes sustainability, since it is produced by agricultural waste. In any case, both of them were successfully thiol-functionalized by applying a twostep process. In particular, they are both treated initially by nitric acid in order to increase the carboxyl groups distribution and then, a thiol carrier molecule (2-mercaptoethanol) was retained on their surface through an esterification reaction in methanol solution in order to limit -SH oxidation. The functionalized materials were tested for the removal of $\mathrm{MeHg}$ from natural-like water in the ppb level, aiming at realistic conditions similar of those to be found in nature. According to the results, the MeHg capacity at $\mathrm{RL}\left(\mathrm{Q}_{1}\right)$ for the D45SH_MeOH material was $0.116 \mu \mathrm{g} / \mathrm{mg}$, whereas that for the SF/KOH-SH_MeOH material was slightly lower (at $0.108 \mu \mathrm{g} / \mathrm{mg}$ ). The aforementioned results cannot be compared with those of the literature, as the value $Q_{1}$ is not used by other researchers for the evaluation of the $\mathrm{Hg}$ adsorption capacity, to the best of our knowledge. Moreover, it was proved that the adsorption mechanism depended on the S-Hg bond formation. As a future work, rapid small-scale continuous-flow column tests (RSSCT) are recommended, since better performance may be expected, due to the different hydrodynamic conditions, which favors the increase in intramolecular diffusion.

Supplementary Materials: The following supporting information can be downloaded at: https:/ / www.mdpi.com/article/10.3390/w14010049/s1, Figure S1: Bacharach cold vapor mercury analyzer system (Coleman-Model 50B); Figure S2: High-resolution C 1s and O 1s core-level XPS spectra of D45-SH_MeOH before $(\mathrm{a}, \mathrm{c})$ and after $(\mathrm{b}, \mathrm{d}) \mathrm{MeHg}$ adsorption.

Author Contributions: Conceptualization, E.K. and A.Z.; methodology, E.K. and A.L.; software, E.K.; validation, E.K., I.K. and A.Z.; formal analysis, E.K.; investigation, E.K. and A.L.; resources, A.Z.; data curation, E.K., A.L., D.K. and I.K.; writing-original draft preparation, E.K.; writing-review and editing, E.K., I.K. and A.Z.; visualization, E.K.; supervision, A.Z.; project administration, E.K.; funding acquisition, A.Z. All authors have read and agreed to the published version of the manuscript.

Funding: This research is co-financed by Greece and the European Union (European Social FundESF) through the Operational Programme «Human Resources Development, Education and Lifelong Learning" in the context of the project "Reinforcement of Postdoctoral Researchers-2nd Cycle" (MIS-5033021), implemented by the State Scholarships Foundation (IK $\Upsilon$ ).

Institutional Review Board Statement: Not applicable.

Informed Consent Statement: Not applicable.

Data Availability Statement: The datasets used and/or analyzed during the current study are available from the corresponding author on reasonable request.

Conflicts of Interest: The authors declare no conflict of interest.

\section{References}

1. Marnane, I. Mercury in Europe's Environment. A Priority for European and Global Action; European Environment Agency: Copenhagen, Denmark, 2018; ISBN 9789292139841.

2. Hong, Y.S.; Kim, Y.M.; Lee, K.E. Methylmercury exposure and health effects. J. Prev. Med. Public Health 2012, 45, 353-363. [CrossRef]

3. United Nations. 2017 Mediterranean Quality Status Report; United Nations: New York, NY, USA, 2017.

4. Kokkinos, E.; Soukakos, K.; Kostoglou, M.; Mitrakas, M. Cadmium, mercury, and nickel adsorption by tetravalent manganese feroxyhyte: Selectivity, kinetic modeling, and thermodynamic study. Environ. Sci. Pollut. Res. 2018, 25, 12263-12273. [CrossRef] [PubMed] 
5. Muller, K.A.; Brandt, C.C.; Mathews, T.J.; Brooks, S.C. Methylmercury sorption onto engineered materials. J. Environ. Manag. 2019, 245, 481-488. [CrossRef]

6. Rehman, A.; Park, M.; Park, S.J. Current progress on the surface chemical modification of carbonaceous materials. Coatings 2019, 9, 103. [CrossRef]

7. Huang, Y.; Gong, Y.; Tang, J.; Xia, S. Effective removal of inorganic mercury and methylmercury from aqueous solution using novel thiol-functionalized graphene oxide/Fe-Mn composite. J. Hazard. Mater. 2019, 366, 130-139. [CrossRef]

8. Kumar, P.S.; Gayathri, R.; Senthil Rathi, B. A review on adsorptive separation of toxic metals from aquatic system using biochar produced from agro-waste. Chemosphere 2021, 285, 131438. [CrossRef]

9. Chen, K.; Zhang, Z.; Xia, K.; Zhou, X.; Guo, Y.; Huang, T. Facile Synthesis of Thiol-Functionalized Magnetic Activated Carbon and Application for the Removal of Mercury(II) from Aqueous Solution. ACS Omega 2019, 4, 8568-8579. [CrossRef] [PubMed]

10. Shen, Y.; Jiang, N.; Liu, S.; Zheng, C.; Wang, X.; Huang, T.; Guo, Y.; Bai, R. Thiol functionalization of short channel SBA-15 through a safe, mild and facile method and application for the removal of mercury (II). J. Environ. Chem. Eng. 2018, 6, 5420-5433. [CrossRef]

11. Li, J.; Xing, X.; Li, J.; Shi, M.; Lin, A.; Xu, C.; Zheng, J.; Li, R. Preparation of thiol-functionalized activated carbon from sewage sludge with coal blending for heavy metal removal from contaminated water. Environ. Pollut. 2018, 234, 677-683. [CrossRef] [PubMed]

12. Huang, Y.; Xia, S.; Lyu, J.; Tang, J. Highly efficient removal of aqueous $\mathrm{Hg}^{2+}$ and $\mathrm{CH}_{3} \mathrm{Hg}^{+}$by selective modification of biochar with 3-mercaptopropyltrimethoxysilane. Chem. Eng. J. 2019, 360, 1646-1655. [CrossRef]

13. ASTM D5373-93. Instrumental Determination of Carbon, Hydrogen and Nitrogen in Laboratory Samples of Coal and Coke; ASTM International: West Conshohocken, PA, USA, 1993. [CrossRef]

14. Kokkinos, E.; Zouboulis, A. Methylmercury determination in sub-ppb level by cold vapor analysis: Facts, mechanisms and optimization. In Proceedings of the 5th International Electronic Conference on Water Sciences, Virtual, 16-30 November 2020; MDPI: Basel, Switzerland, 2020. [CrossRef]

15. Li, Z.; Wu, L.; Liu, H.; Lan, H.; Qu, J. Improvement of aqueous mercury adsorption on activated coke by thiol-functionalization Chem. Eng. J. 2013, 228, 925-934. [CrossRef]

16. Daud, W.M.A.W.; Houshamnd, A.H. Textural characteristics, surface chemistry and oxidation of activated carbon. J. Nat. Gas Chem. 2010, 19, 267-279. [CrossRef]

17. Hadavifar, M.; Bahramifar, N.; Younesi, H.; Li, Q. Adsorption of mercury ions from synthetic and real wastewater aqueous solution by functionalized multi-walled carbon nanotube with both amino and thiolated groups. Chem. Eng. J. 2014, 237, 217-228. [CrossRef]

18. Xia, S.; Huang, Y.; Tang, J.; Wang, L. Preparation of various thiol-functionalized carbon-based materials for enhanced removal of mercury from aqueous solution. Environ. Sci. Pollut. Res. 2019, 26, 8709-8720. [CrossRef]

19. Freundlich, H. Over the adsorption in solution. J. Phys. Chem. 1906, 57, 1100-1107.

20. Langmuir, I. The constitution and fundamental properties of solids and liquids. Part I. Solids. J. Am. Chem. Soc. 1916, 38, 2221-2295. [CrossRef]

21. Kokkinos, E.; Chousein, C.; Simeonidis, K.; Coles, S.; Zouboulis, A.; Mitrakas, M. Improvement of manganese feroxyhyte's surface charge with exchangeable $\mathrm{Ca}$ ions to maximize $\mathrm{Cd}$ and $\mathrm{Pb}$ uptake from water. Materials 2020, 13, 1762. [CrossRef]

22. Jeon, K.W. Easily processable, highly transparent and conducting thiol-functionalized reduced graphene oxides langmuir-blodgett films. Molecules 2021, 26, 2686. [CrossRef]

23. Munir, A.; Haq, T.U.; Qurashi, A.; Rehman, H.U.; Ul-Hamid, A.; Hussain, I. Ultrasmall Ni/NiO nanoclusters on thiolfunctionalized and-exfoliated graphene oxide nanosheets for durable oxygen evolution reaction. ACS Appl. Energy Mater. 2019, 2, 363-371. [CrossRef]

24. Chai, L.; Li, Q.; Zhu, Y.; Zhang, Z.; Wang, Q.; Wang, Y.; Yang, Z. Synthesis of thiol-functionalized spent grain as a novel adsorbent for divalent metal ions. Bioresour. Technol. 2010, 101, 6269-6272. [CrossRef]

25. Kokkinos, E.; Simeonidis, K.; Pinakidou, F.; Katsikini, M.; Mitrakas, M. Optimization of tetravalent manganese feroxyhyte's negative charge density: A high-performing mercury adsorbent from drinking water. Sci. Total Environ. 2017, 574, 482-489. [CrossRef]

26. Zhang, Z.; Xia, K.; Pan, Z.; Yang, C.; Wang, X.; Zhang, G.; Guo, Y.; Bai, R. Removal of mercury by magnetic nanomaterial with bifunctional groups and core-shell structure: Synthesis, characterization and optimization of adsorption parameters. Appl. Surf. Sci. 2020, 500, 143970. [CrossRef]

27. Liang, R.; Zou, H. Removal of aqueous $\mathrm{Hg}$ (ii) by thiol-functionalized nonporous silica microspheres prepared by one-step sol-gel method. RSC Adv. 2020, 10, 18534. [CrossRef]

28. Zhang, S.; Zhang, Y.; Liu, J.; Xu, Q.; Xiao, H.; Wang, X.; Xu, H.; Zhou, J. Thiol modified $\mathrm{Fe}_{3} \mathrm{O}_{4} @ S i \mathrm{O}_{2}$ as a robust, high effective, and recycling magnetic sorbent for mercury removal. Chem. Eng. J. 2013, 226, 30-38. [CrossRef]

29. Zhang, X.; Wu, T.; Zhang, Y.; Ng, D.H.L.; Zhao, H.; Wang, G. Adsorption of $\mathrm{Hg}^{2+}$ by thiol functionalized hollow mesoporous silica microspheres with magnetic cores. RSC Adv. 2015, 5, 51446-51453. [CrossRef] 